\title{
Asymmetric Anisoin Synthesis Involving Benzoin Condensation Followed by Deracemization
}

Aoi Washio, ${ }^{[\mathrm{a}]}$ Momoka Hosaka, ${ }^{[\mathrm{a}]}$ Naohiro Uemura, ${ }^{[\mathrm{a}]}$ Yasushi Yoshida, ${ }^{[\mathrm{a}],[\mathrm{b}]}$ Takashi Mino, ${ }^{[\mathrm{a}],[\mathrm{b}]}$ Yoshio Kasashima, ${ }^{[\mathrm{c}]}$ and Masami Sakamoto, ${ }^{[\mathrm{a}],[\mathrm{b}]}$

[a] Department of Applied Chemistry and Biotechnology, Graduate School of Engineering, Chiba University, Yayoi-cho, Inage-ku, Chiba 263-8522, Japan

${ }^{[b]}$ Molecular Chirality Research Center, Chiba University, Yayoi-cho, Inage-ku, Chiba 263-8522, Japan

[c] Education Center, Faculty of Creative Engineeing, Chiba Institute of Technology, Shibazono, Narashino, Chiba 275-0023, Japan 


\section{Table of Contents}

General infromation

Racemization of 1

Single crystal X-ray structure analysis of 1

Attrition-enhanced deracemization racemic 1

One-pot asymmetric synthesis of 1

Attrition-enhanced deracemization racemic 1 with valine S5

Asymmetric synthesis of 1 by thiamine hydrochloride (C1) with asymmetric control by added L or D-valine

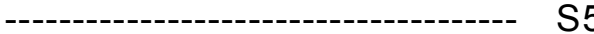

HPLC analysis of 1 


\section{General information}

NMR spectra were recorded in $\mathrm{CDCl}_{3}$ solutions on Bruker DPX 300 and DPX 400 spectrometers for ${ }^{1} \mathrm{H}-$ and ${ }^{13} \mathrm{C}-\mathrm{NMR}$. Chemical shifts are reported in parts per million $(\mathrm{ppm})$ relative to TMS as an internal standard. The measurement for X-ray crystallographic analysis was made on a Bruker SMART APEXII CCD area detector with monochromated Mo-Ka radiation. The structure was solved by direct methods with SHELXL-97 andrefined with SHELXL-2014/7. Crystallographic data have been deposited with the Cambridge Crystallographic Data Centre. HPLC analyses were performed on a JASCO HPLC system (JASCO PU-1580 pump, DG-1580-53, LG-2080-02, MD-2015, UV-2075, and CD-2095 detector). Chiral column CHIRALPAK OD-H (Daicel Ind.) was used for HPLC analysis. Commercially available $p$ methoxybenzaldehyde, p-anisoin, 3-benzyl-5-(2-hydroxyethyl)-4-methylthiazolium chloride, 1-ethyl-3methylimidazolium bromide, thiamine hydrochloride and DBU were used without further purification.

\section{Racemization of 1.}

A variety of solutions of $1(27.2 \mathrm{mg}, 0.1 \mathrm{mmol}, 0.01 \mathrm{M})$ and DBU $(1.5 \mathrm{mg}, 0.01 \mathrm{mmol})$ were stirred at $25^{\circ} \mathrm{C}$. The time course of enantiomeric excess was monitored by HPLC (CHIRALPAK OD-H, Hex: 2-PrOH = 90 : 10, flow $0.7 \mathrm{~mL} / \mathrm{min}, \mathrm{RT}=33.0$ and $37.5 \mathrm{~min}$ ).

\section{Single crystal $X$-ray structure analysis of $p$-anisoin 1}

Colorless plate, $\left(0.50 \times 0.20 \times 0.20 \mathrm{~mm}^{3}\right)$, orthorhombic space group $P 2{ }_{1}{ }_{1}{ }_{1}{ }_{1}, a=5.9552(7) \AA, b=$ 11.9920(14) $\AA, c=18.811(2) \AA, V=1343.4(3) \AA^{3}, Z=4, \lambda(\operatorname{MoK} \alpha)=0.71073 \AA, \rho=1.346 \mathrm{~g} / \mathrm{cm}^{3}, \mu$ $($ CuK $\alpha)=0.096 \mathrm{~mm}^{-1}, 7610$ reflections measured $\left(T=173 \mathrm{~K}, 2.014^{\circ}<\theta<27.372^{\circ}\right)$, nb of independent data collected: $2990, \mathrm{nb}$ of independent data used for refinement: 2784 in the final least-squares refinement cycles on $\mathrm{F}^{2}$, the model converged at $R_{1}=0.0310, w R_{2}=0.0748[\mathrm{I}>2 \sigma(\mathrm{I})], R_{1}=0.0316, w R_{2}$ $=0.0770$ (all data), and GOF = 1.044, $\mathrm{H}$-atom parameters constrained.

CCDC 2053909 contains the supplementary crystallographic data for this paper. These data can be obtained free of charge from The Cambridge Crystallographic Data Centre. 


\section{Attrition-enhanced deracemization of racemic 1}

To a sealed glass tube $(\varnothing 20 \mathrm{~mm})$ were added 1 (272 mg, $1.0 \mathrm{mmol})$, EtOH $(0.5 \mathrm{~mL}), \mathrm{DBU}(15 \mathrm{mg}, 0.10$ $\mathrm{mmol}$ ), and glass beads ( $\varnothing 2 \mathrm{~mm}, 20$ pieces), and the mixture was suspended with stirring at $600 \mathrm{rpm}$ using a cross-shaped stirring bar $(15 \mathrm{~mm})$ at $60{ }^{\circ} \mathrm{C}$. Crystals obtained by filtration at regular intervals were subjected to HPLC (CHIRALPAK OD-H, Hex: 2-PrOH = $90: 10$, flow $0.7 \mathrm{~mL} / \mathrm{min}, \mathrm{RT}=33.0$ and $37.5 \mathrm{~min}$ ) to determine the enantiomeric purity. Crystals were recovered in $90-91 \%$ yields with $96-99 \%$ ee. Thirteen experiments converged to (+)-1 for seven and (-)-1 for six without any additives.

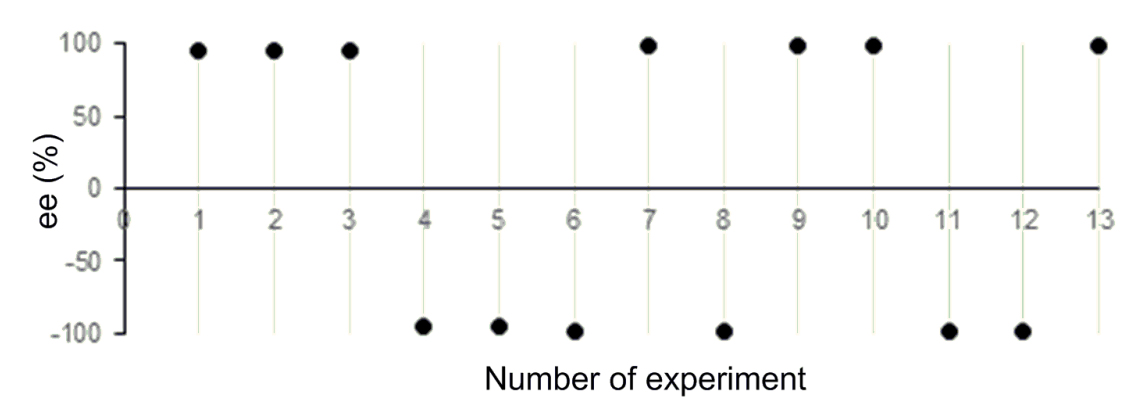

Figure S1. Attrition-enhanced deracemization racemic 1 without any additives

\section{Attrition-enhanced deracemization of racemic 1 in a gram scale.}

To a sealed glass tube $(\varnothing 20 \mathrm{~mm})$ were added racemic $1(2.2 \mathrm{~g}, 8.0 \mathrm{mmol})$, EtOH $(2.0 \mathrm{~mL}), \mathrm{DBU}(120$ $\mathrm{mg}, 0.8 \mathrm{mmol}$ ), and glass beads ( $\varnothing 2 \mathrm{~mm}, 35$ pieces), and the mixture was suspended with stirring at 600 rpm using cross-shaped stirring bar $(15 \mathrm{~mm})$ at $60^{\circ} \mathrm{C}$. Crystals obtained by filtration were subjected to HPLC using CHIRALPAK OD-H to determine the enantiomeric excess. Crystals were recovered in $90 \%$ yield and $99 \%$ ee.

One-pot asymmetric synthesis of 1 from prochiral p-anisaldehyde using vitamin $B_{1}$ (C1).

To a sealed glass tube $(\varnothing 20 \mathrm{~mm})$ were added $p$-anisaldehyde $(272 \mathrm{mg}, 2.0 \mathrm{mmol}), \mathrm{EtOH}(0.5 \mathrm{~mL}), \mathbf{C} 1(60$ $\mathrm{mg}, 0.2 \mathrm{mmol}$ ) sodium hydroxide aqueous solution $(0.5 \mathrm{~mL}, 0.6 \mathrm{M})$, and glass beads $(\varnothing 2 \mathrm{~mm}, 20$ pieces), and the mixture was stirred at room temperature for $24 \mathrm{~h}$. After the condensation reaction was complete, the solvent was evaporated under reduced pressure to remove the water. To the crude racemic $p$-anisoin was added $\mathrm{EtOH}(0.5 \mathrm{~mL})$, which was suspended with stirring at $600 \mathrm{rpm}$ using cross-shaped stirring bar $(15 \mathrm{~mm})$ at $60^{\circ} \mathrm{C}$. Crystals of 1 were obtained by filtration in $70 \%$ yield with $93 \%$ ee.

One-pot asymmetric synthesis of 1 from prochiral p-anisaldehyde using 3-benzyl-5-(2-hydroxyethyl)-4methylthiazolium chloride (C2) with $\mathrm{NaOH}$.

To a sealed glass tube $(\varnothing 20 \mathrm{~mm})$ were added $p$-anisaldehyde $(272 \mathrm{mg}, 2.0 \mathrm{mmol}), \mathrm{EtOH}(0.5 \mathrm{~mL}), \mathbf{C 2}$ 
(54 mg, $0.2 \mathrm{mmol}$ ), $\mathrm{NaOH}$ (12 mg, $0.30 \mathrm{mmol}$ ), and glass beads ( $\varnothing 2 \mathrm{~mm}, 20$ pieces), and the mixture was suspended with stirring at $600 \mathrm{rpm}$ using cross-shaped stirring bar $(15 \mathrm{~mm})$ at $60^{\circ} \mathrm{C}$. Crystals obtained by filtration were subjected to HPLC to determine the enantiomeric purity. The solvent was removed under reduced pressure to give the crude product 1 . Crystals of 1 were obtained by filtration in $75 \%$ yield with $99 \%$ ee.

One-pot asymmetric synthesis of 1 from prochiral aldehyde 1a using 3-benzyl-5-(2-hydroxyethyl)-4methylthiazolium chloride (C2) with $D B U$.

To a sealed glass tube $(\varnothing 20 \mathrm{~mm})$ were added $p$-anisaldehyde $(272 \mathrm{mg}, 2.0 \mathrm{mmol}), \mathrm{EtOH}(0.5 \mathrm{~mL}), \mathbf{C 2}$ (54 mg, $0.2 \mathrm{mmol}$ ), DBU (45 mg, $0.30 \mathrm{mmol}$ ), and glass beads ( $\varnothing 2 \mathrm{~mm}, 20$ pieces), and the mixture was suspended with stirring at $600 \mathrm{rpm}$ using cross shape stirring bar $(15 \mathrm{~mm})$ at $60^{\circ} \mathrm{C}$. Crystals were obtained by filtration in $50 \%$ yield and $94 \%$ ee.

One-pot absolute asymmetric synthesis of 1 from p-anisaldehyde using 1-ethyl-3-methylimidazolium bromide (C3) with $\mathrm{NaOH}$.

To a sealed glass tube $(\varnothing 20 \mathrm{~mm})$ were added $p$-anisaldehyde $(273 \mathrm{mg}, 2.0 \mathrm{mmol}), \mathrm{EtOH}(0.5 \mathrm{~mL}), \mathbf{C} 3$ (38mg, $0.2 \mathrm{mmol}), \mathrm{NaOH}(12.0 \mathrm{mg}, 0.3 \mathrm{mmol}$ ), and glass beads $(\varnothing 2 \mathrm{~mm}, 20$ pieces), and the mixture was suspended with stirring at $600 \mathrm{rpm}$ using cross-shaped stirring bar $(15 \mathrm{~mm})$ at $60{ }^{\circ} \mathrm{C}$. Crystals were obtained by filtration in $88 \%$ yield with $99 \%$ ee.

Asymmetric control of racemic 1 via attrition-enhanced deracemization with $L$ or $D$-valine.

To a sealed glass tube $(\varnothing 20 \mathrm{~mm})$ were added racemic 1 (272 mg, $1.0 \mathrm{mmol})$, L or D-amino acid (12 mg, $0.1 \mathrm{mmol}), \mathrm{EtOH}(0.5 \mathrm{~mL}), \mathrm{DBU}(30 \mathrm{mg}, 0.20 \mathrm{mmol})$, and glass beads $(\varnothing 2 \mathrm{~mm}, 20$ pieces), and the mixture was suspended with stirring at $600 \mathrm{rpm}$ using cross-shaped stirring bar $(15 \mathrm{~mm})$ at $60{ }^{\circ} \mathrm{C}$ for 5 days. Crystals obtained by filtration were subjected to HPLC with CHIRALPAK OD-H to determine the enantiomeric purity. Crystals were recovered in $88-91 \%$ yield with $>99 \%$ ee.

Asymmetric synthesis of 1 by thiamine hydrochloride (C1) with asymmetric control by added L or D-valine.

To a sealed glass tube were added $p$-anisaldehyde $(272 \mathrm{mg}, 2.0 \mathrm{mmol})$, $\mathrm{L}$ or D-amino acid (12 $\mathrm{mg}, 0.1$ $\mathrm{mmol}), \mathrm{EtOH}(0.5 \mathrm{~mL}), \mathbf{C} 1(60 \mathrm{mg}, 0.2 \mathrm{mmol})$ sodium hydroxide aqueous solution $(0.5 \mathrm{~mL}, 0.6 \mathrm{M})$ and glass beads, and the mixture was stirred at room temperature for 24 hours. After the solvent was evaporated under reduced pressure, $\mathrm{EtOH}(0.5 \mathrm{~mL})$ was added and suspended with stirring at $600 \mathrm{rpm}$ at $60{ }^{\circ} \mathrm{C}$. Crystals were recovered by filtration in $68-70 \%$ yield with $>99 \%$ ee. 


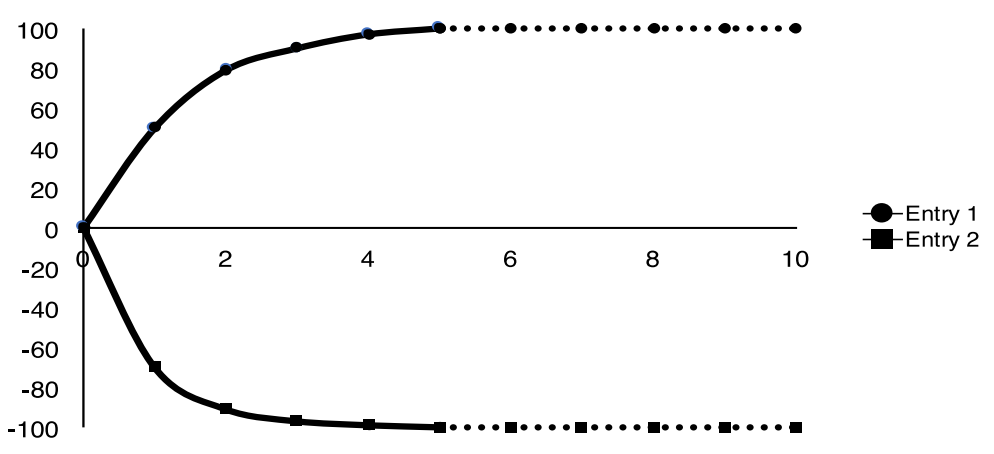

Figure S2. The time course of ees of 1 involving asymmetric control using L-valine (Table 4, entry 1 ) or Dvaline (Table 4, entry 2). 
Figure S3. HPLC analysis of racemic 1.

\section{CD trace at $254 \mathrm{~nm}$}

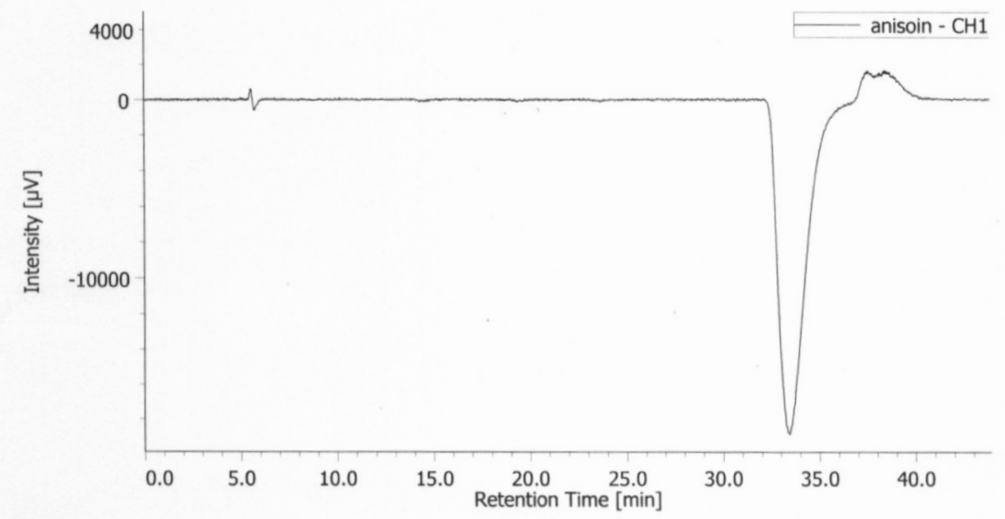

UV trace at $254 \mathrm{~nm}$

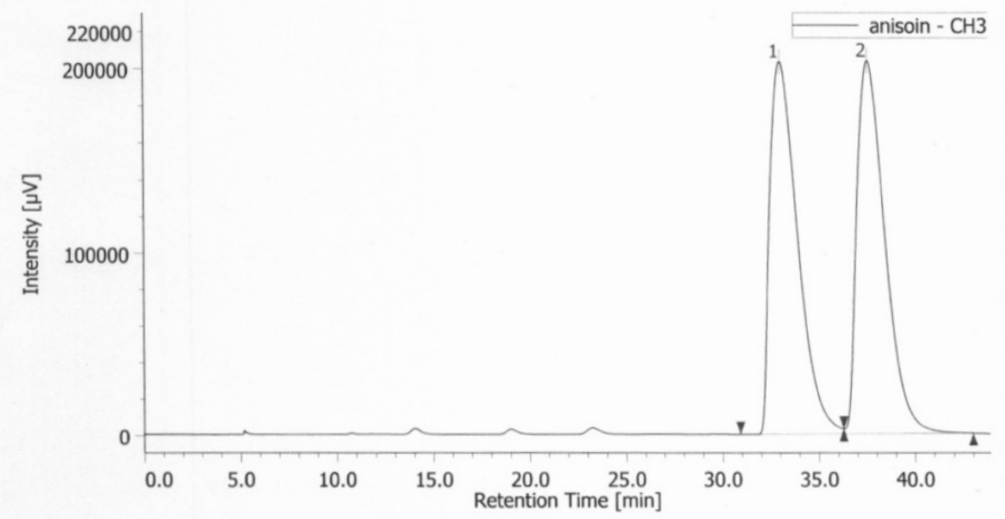

Column: OD-H

Flow rate: $0.7 \mathrm{~mL} / \mathrm{min}$

Eluent: Hexane : 2-PrOH $=90: 10$ 
Figure S4. HPLC analysis of $99 \%$ ee of $(S)-(+)-1$.

CD trace at $254 \mathrm{~nm}$

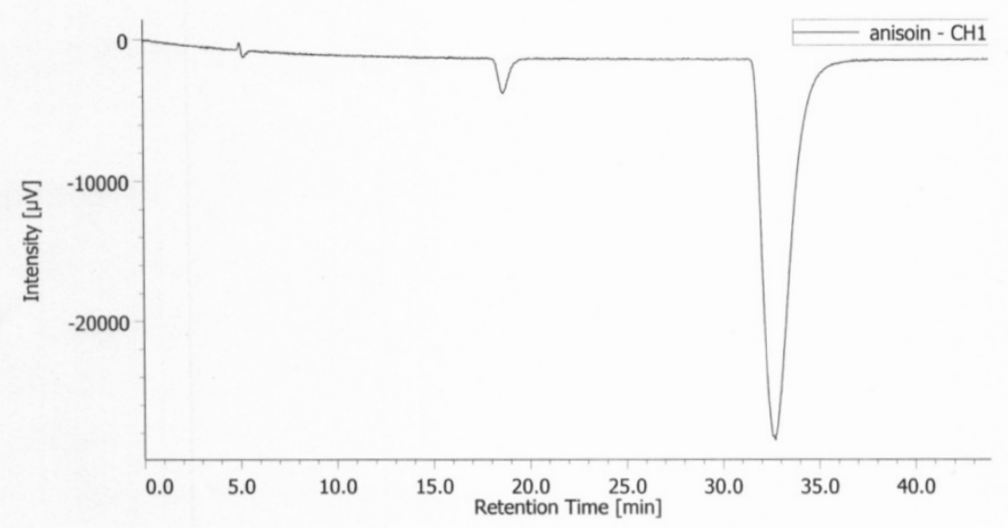

UV trace at $254 \mathrm{~nm}$

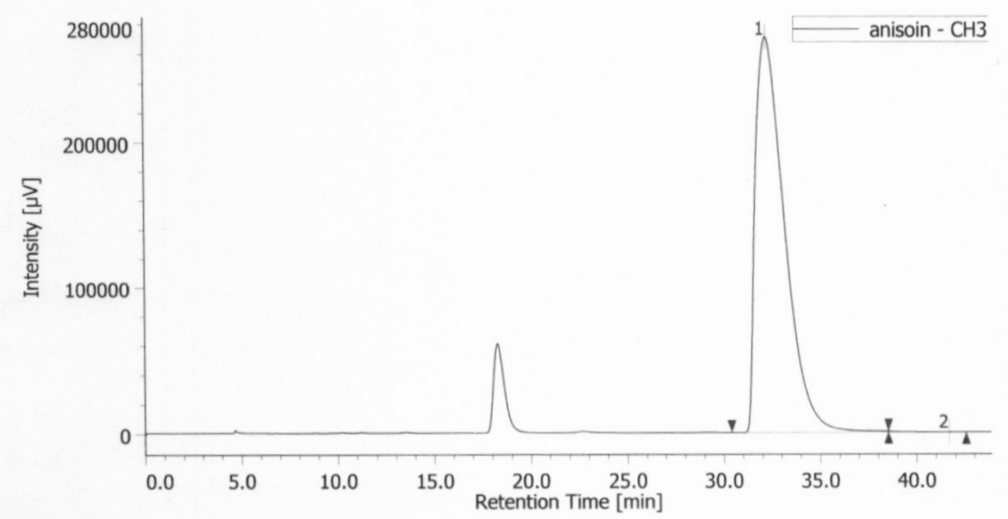

Column: OD-H

Flow rate: $0.7 \mathrm{~mL} / \mathrm{min}$

Eluent: Hexane : 2-PrOH = $90: 10$ 